\title{
Up-regulation of the phosphatidylinositol 3-kinase/protein kinase B pathway in the ovary of rats by chronic treatment with hCG and insulin
}

\author{
Maria H M Lima ${ }^{1,3}$, Lílian C Souza ${ }^{1}$, Luciana C Caperuto ${ }^{1}$, Estela Bevilacqua ${ }^{2}$, Alessandra L Gasparetti ${ }^{4}$, \\ Ricardo Zanuto ${ }^{1}$, Mario J A Saad ${ }^{4}$ and Carla R O Carvalho ${ }^{1}$ \\ ${ }^{1}$ Department of Physiology and Biophysics and ${ }^{2}$ Department of Cellular and Development Biology, Institute of Biomedical Sciences, University of Sao Paulo \\ (USP), ${ }^{3}$ Department of Nursing and ${ }^{4}$ Department of Internal Medicine, Medical Sciences Faculty, University of Campinas (UNICAMP), Brazil \\ (Requests for offprints should be addressed to C R O Carvalho, Departamento de Fisiologiae Biofísica, ICB-USP, Rua Prof. Lineu Prestes, 1524, sala 121, ICB1, \\ Cidade Universitária, Butantã, São Paulo, SP, Brazil, 055096-900; Email: croc@icb.usp.br)
}

\begin{abstract}
Polycystic ovary syndrome (PCOS) manifests as chronic anovulation, ovarian hyperandrogenism, and follicular cysts, which are amplified by insulin as well as the inability of the hormone to stimulate glucose uptake in classic target tissues such as muscle and fat. In the present study, we evaluated the regulation of the insulin-signaling pathways by using immunoprecipitation and immunoblotting in whole extracts of ovaries from non-pregnant human chorionic gonadotropin (hCG)-treated rats, hyperinsulinemic-induced rats and hyperinsulinemic-induced rats, treated with hCG for 22 consecutive days. There were increased associations of insulin receptor substrate (IRS)-1 and IRS-2 with phosphatidylinositol (PI) 3-kinase, followed by enhanced protein kinase B
\end{abstract}

(Akt) serine and threonine phosphorylation, in the ovaries of rats that were treated with hCG, either alone or with insulin. In contrast, the skeletal muscle demonstrated a reduced IRS1/PI 3-kinase/Akt pathway in hyperinsulinemic-induced rats. These intracellular modifications were accompanied by follicular cysts, detected by optical microscopy, and increased androstenedione serum levels. In summary, our data show that chronic treatment with hCG or hCG plus insulin can induce changes in ovaries that simulate PCOS. In these situations, an increase in the insulin-induced IRS/PI 3-kinase/Akt pathway occurs in the ovary, suggesting that the activation of this pathway may have a role in the development of PCOS.

Journal of Endocrinology (2006) 190, 451-459

\section{Introduction}

Insulin acts by binding to its receptor, stimulating autophosphorylation and activation of the insulin receptor, intrinsic tyrosine kinase. This effect leads to recruitment and phosphorylation of members of the insulin receptor substrate (IRS) protein family (IRS-1-4). Once the IRS proteins are tyrosine phosphorylated, they act as an anchor for various src homology 2 domain-containing proteins, such as the p85 regulatory subunit of phosphatidylinositol (PI) 3-kinase and phosphotyrosine phosphatase (SHP2). IRS association with the p85 subunit of the PI 3-kinase activates the p110 catalytic subunit of PI 3-kinase, which mediates the phosphorylation of phosphatidylinositol 3,4,5 triphosphate, a key signaling intermediate that recruits and activates downstream molecules, including serine-threonine kinases, tyrosine kinases, GTPases, and others. Protein kinase B (PKB)/Akt is one key downstream target of PI 3-kinase, activated by serine and threonine phosphorylation. Akt is activated and its phosphorylation appears to be the primary mechanism by which enzymatic activity is regulated. Upon insulin receptor, tyrosine kinase activation and autophosphorylation, there is also recruitment of Shc protein and Grb2, leading to activation of the extracellular signal-regulated kinase (ERK) pathway (Saltiel \& Kahn 2002, Saltiel \& Pessin 2002).

Insulin has a stimulatory effect on steroidogenesis by granulosa cells from cow, rats, and women and interacts with luteinizing hormone (LH) in a synergistic manner, enhancing human chorionic gonadotropin (hCG)-induced ovarian growth and cyst formation (Franks et al. 1999). Evidence indicates that the insulin effect is mediated through the insulin receptor and not the type I insulin-like growth factor (IGF) receptor (Willis \& Franks 1995, Nestler et al. 1998). We previously demonstrated a new intracellular pathway for LH/ hCG, showing that there is a positive crosstalk between insulin and the LH/hCG signaling pathway at the level of the PI 3-kinase/Akt pathway in the ovary of non-pregnant rats (Carvalho et al. 2003). In addition, it is well established that both insulin resistance and consequent hyperinsulinemia have an important role in the pathogenesis of polycystic ovary syndrome (PCOS) (Dunaif et al. 1989, Dunaif 1997). PCOS manifests as chronic anovulation and ovarian hyperandrogenism, both of which are amplified by insulin, in addition to the inability of the hormone to stimulate glucose uptake in classic 
target tissues such as muscle and fat (Dunaif 1997, Legro et al. 1999, Poretsky et al. 1999). However, the regulation of insulin signaling in ovaries of rats with PCOS has not yet been investigated.

In the present study, we assessed the regulation of the insulin-signaling pathways using immunoprecipitation and immunoblotting in whole extracts of ovaries from hCGtreated rats, hyperinsulinemic-induced rats, and hyperinsulinemic-induced rats treated with hCG. Basal and acute insulin-induced phosphorylation of insulin receptor (IR), IRS-1, IRS-2, Akt, and ERK and the association of IRS proteins with PI 3-kinase were examined.

\section{Materials and Methods}

\section{Materials}

The reagents for SDS-PAGE, immunoprecipitation and immunoblotting were from Bio-Rad. High-purified hCG was from two sources: NIDDK's National Hormone and Pituitary Program (Torrance, CA, USA) and Calbiochem (San Diego, CA, USA). Human recombinant insulin (Biohulin and Iolin R) was from Biobras (MG, Brazil). Anti-IR, anti-IRS-1, anti-IRS-2, anti-SHP2, antiphosphotyrosine, and phospho-threonine Akt (Thr308) antibodies were from Santa Cruz Technology (Santa Cruz, CA, USA). Anti-PI 3-kinase was from Upstate Biotechnology Incorporated (Lake Placid, NY, USA). Both phospho-Akt (Ser473) and phospho-ERK (Thr202/Tyr204) antibodies were from Cell Signaling (Beverly, MA, USA). The enhanced chemiluminescence reagent kit, ECL, and protein A Sepharose $6 \mathrm{MB}$ were from Amersham-Pharmacia Biotech.

\section{Animal tissue extracts}

Female Wistar rats (200-220 g) were housed with access to standard rodent chow and water ad libitum. All procedures with animals were conducted in accordance with the principles and procedures described by the NIH Guidelines for Care and Use of Experimental Animals and approved by the Ethics Committee for Animal Handling of the Instituto de Ciencias Biomedicas/USP. The rats were divided into four groups: control, hCG-treated, insulin-treated and hCG plus insulin-treated. The treatment protocol was composed of s.C. injections of saline (control animals), daily 3 IU hCG and insulin in order to obtain a hyperinsulinemic state. Briefly, saline and the hormones were administered twice a day, insulin injections started with $0.5 \mathrm{IU} /$ day and gradually increased to $6 \mathrm{IU} /$ day from the 11 th day until the 22 nd day (Poretsky et al. 1992). On the 23rd day, $14 \mathrm{~h}$ after the last hormone administration, the rats were anesthetized with sodium thiopental (25 mg/kg, i.p.; Cristalia, São Paulo, Brazil) and used 10-15 min later, as soon as anesthesia was assured by the loss of pedal and corneal reflexes.

\section{Morphology of the ovaries}

The ovaries from anesthetized rats were excised and dissected free from the surrounding tissues and fixed by immersion in $4 \%$ formaldehyde-PBS solution for 4-6 h and transferred to a $30 \%$ sucrose solution in PBS for cryoprotection. The paraformaldehyde-fixed and paraffin-embedded ovaries sections $(5 \mu \mathrm{m})$ were counterstained with hematoxylin-eosin for morphological analysis. The ovary morphology was analyzed using a conventional light microscope.

\section{Immunoblotting analysis}

The abdominal cavity of anesthetized rats was opened, the cava vein exposed, and $0.5 \mathrm{ml}$ saline $(0.9 \% \mathrm{NaCl})$ with or without $6 \mu \mathrm{g}$ insulin was injected as a bolus infusion. The ovaries were removed $5 \mathrm{~min}$ after the injection, which corresponded to the maximal insulin-induced IR, IRS-1 and IRS-2 tyrosyl phosphorylation (data not shown), and homogenized in ice-cold extraction buffer containing $100 \mathrm{mM}$ Tris (pH: 7.4), $10 \mathrm{mM}$ EDTA, 1\% Triton-X100, $100 \mathrm{mM}$ sodium fluoride, $10 \mathrm{mM}$ sodium pyrophosphate, $10 \mathrm{mM}$ sodium vanadate, $2 \mathrm{mM}$ phenylmethylsulfonylfluoride, and $0 \cdot 01 \mathrm{mg}$ aprotinin/ml (Sigma). Pooled ovary extracts from rats were centrifuged at $15000 \mathrm{rpm}, 4^{\circ} \mathrm{C}$, for $15 \mathrm{~min}$ to remove insoluble material; the supernatant was then used for the assay. The hind limb gastrocnemius muscle was also removed $90 \mathrm{~s}$ after insulin injection and processed as described above for the ovary. Protein determination was performed by the Bradford dye binding method using the Bio-Rad reagent and BSA as the standard. Two or three milligrams protein from the supernatant was used for immunoprecipitation with antiIR, anti-IRS-1, anti-IRS-2, and protein A-Sepharose $6 \mathrm{MB}$ before Laemmli sample buffer treatment and electrophoresis in SDS-PAGE (Bio-Rad), as described elsewhere (Carvalho et al. 2003). For whole tissue extracts, similar-sized aliquots $(100 \mu \mathrm{g}$ protein) were subjected to SDS-PAGE and subsequently to typical immunoblotting. Electrotransfer of proteins from the gel to nitrocellulose was performed for $90 \mathrm{~min}$ at $120 \mathrm{~V}$ (constant). To reduce non-specific protein binding to the nitrocellulose, the filter was pre-incubated overnight at $4{ }^{\circ} \mathrm{C}$ in blocking buffer (5\% non-fat dry milk, $10 \mathrm{mM}$ Tris, $150 \mathrm{mM} \mathrm{NaCl}$ and $0 \cdot 02 \%$ Tween 20; Sigma). The nitrocellulose blots were incubated overnight at $22^{\circ} \mathrm{C}$ with antibodies against phosphotyrosine, the p85 subunit of PI 3-kinase, the p95 subunit of IR, IRS-1, IRS-2, pAkt (pSer-Akt and pThr-Akt), and pERK diluted in blocking buffer with $3 \%$ non-fat dry milk followed by washing for $30 \mathrm{~min}$ in blocking buffer without milk. To visualize the autoradiogram, commercial enhanced chemiluminescence reagents exposed to photographic film were used. Quantitative analysis of the blots was performed using Scion Image software (Frederick, MD, USA). 


\section{Radioimmunoassay}

Insulin, luteinizing hormone (LH), androstenedione, and estradiol were determined by standard RIA.

\section{Statistical analysis}

The results were expressed as the mean \pm s.E.M. ANOVA factorial test was used in all statistical comparisons with $P<0 \cdot 05$ indicating significance.

\section{Results}

Serum insulin, luteinizing hormone, androstenedione, and estradiol levels

Table 1 shows the effect of various treatments on mean serum levels of insulin, LH, androstenedione, and estradiol. Insulin concentrations were sevenfold increased in groups that received insulin injections. Serum LH concentrations were significantly increased in all treated groups, compared with controls (C: $0 \cdot 40 \pm 0 \cdot 02$; hCG: $1 \cdot 02 \pm 0 \cdot 36$; hCG + insulin: $4 \cdot 46 \pm 2 \cdot 91$; insulin: $0 \cdot 87 \pm 0 \cdot 02 \mathrm{ng} / \mathrm{ml}, P<0 \cdot 05)$.

Serum androstenedione levels were significantly elevated for rats that received either hCG alone $(0 \cdot 77 \pm 0 \cdot 11 \mathrm{ng} / \mathrm{ml})$, or hCG plus insulin $(1 \cdot 09 \pm 0 \cdot 13 \mathrm{ng} / \mathrm{ml})$ compared with the control. In contrast, serum estradiol concentrations were similar in all groups.

\section{Ovarian morphology}

Figure 1 illustrates the histological examination of representative ovaries from all groups. In the control (Fig. 1A), the ovarian parenchyma consists of follicles in different developmental phases, which comprise primordial follicles until mature, or Graafian follicles. Follicular cells, zona pellucida, theca cells, and interstitial cells exhibit normal characteristics particular to the ovarian follicular phase in a cyclic young female.

Ovaries from hCG-treated females presented an unusual number of fluid-filled cysts within or on the surface of the organ (Fig. 1B, C). Some of these cysts appeared to arise from differentiating follicles but others from corpus luteum. In the follicles containing a cystic center, the layer of lining of follicular cells frequently exhibited an abnormal morphology and organization.

Follicles in the final developmental phases share the ovarian parenchyma with numerous corpora lutea in the group of females that received insulin (Fig. 1D). The morphological analysis revealed two distinct characteristics resulting from this treatment; the corpora lutea did not reach the size of those found in the controls and the persistent interstitial cells were numerous and unusually arranged in cord-like clusters (Fig. 1E). The optically clear cytoplasm, however, suggested steroidogenic activity.

With the exception of extremely cystic structures, the morphology of the ovaries from LH-insulin-treated females seemed quite normal. Follicles in different phases of maturation formed the ovarian parenchyma (Fig. 1F). The cell layers and organization of these structures exhibited no changes. Cysts were still present similar to those found in LH-treated animals and were similarly also derived from differentiating follicles and corpus luteum. The lining wall of the cystic fluid was usually deeply altered and typical follicular cells were hardly/barely recognized (Fig. 1G).

Insulin receptor, IRS-1, IRS-2, PI 3-kinase, Akt, ERK1, and ERK2 protein levels and phosphorylation degrees in ovarian tissue homogenates

Figure 2A shows the effect of the treatment protocol on the insulin receptor protein level and tyrosine phosphorylation in the ovaries of intact rats. There was no change in the insulin receptor levels, as determined by immunoblotting with a specific antibody. In ovary samples immunoprecipitated previously with anti-insulin receptor antibody and immunoblotted with antiphosphotyrosine antibody, there was a statistically significant twofold increase $(P<0 \cdot 05)$ in the insulin-stimulated phosphorylation of the insulin receptor in hCG plus insulin-treated rats when compared with the controls, hCG alone, and insulin-alone treatments (Fig. 2A, bar graph).

Using the specific anti-peptide antibody against IRS-1 (Fig. 2B), the levels of this protein were similar in all four groups. All conditions were similar in the basal tyrosine phosphorylation. After acute insulin infusion, all groups demonstrated an increase in the IRS-1 tyrosine phosphorylation above each basal. Comparisons between

Table 1 Serum levels of insulin, LH, androstenedione (A), and estradiol (E) of control and hormone-treated female rats after 22 consecutive days with human chorionic gonadotropin (hCG) or insulin or hCG plus insulin

\begin{tabular}{|c|c|c|c|c|}
\hline & Insulin $(\mu \mathrm{U} / \mathrm{ml})$ & $\mathbf{L H}(\mathrm{ng} / \mathrm{ml})$ & $\mathbf{A}(\mathrm{ng} / \mathrm{ml})$ & $\mathbf{E}(\mathrm{ng} / \mathrm{ml})$ \\
\hline \multicolumn{5}{|l|}{ Group } \\
\hline Control & $25 \pm 10^{a}(10)$ & $0 \cdot 40 \pm 0 \cdot 02^{\mathrm{a}}(4)$ & $0 \cdot 45 \pm 0 \cdot 08^{\mathrm{a}}(4)$ & $48 \cdot 1 \pm 15 \cdot 9^{a}(4)$ \\
\hline hGC & $24 \pm 8^{\mathrm{a}}(5)$ & $1 \cdot 02 \pm 0 \cdot 36^{b}(5)$ & $0 \cdot 77 \pm 0 \cdot 11^{\mathrm{b}}(5)$ & $73 \cdot 4 \pm 10 \cdot 7^{\mathrm{a}}(5)$ \\
\hline hGC plus insulin & $179 \pm 63^{b}(5)$ & $4 \cdot 46 \pm 2 \cdot 91^{b}(4)$ & $1 \cdot 09 \pm 0 \cdot 13^{b}(4)$ & $234 \cdot 9 \pm 204 \cdot 8^{a}$ \\
\hline Insulin & $169 \pm 57^{b}(10)$ & $0 \cdot 87 \pm 0 \cdot 02^{b}(5)$ & $0 \cdot 51 \pm 0 \cdot 16^{\mathrm{ab}}(5)$ & $34 \cdot 4 \pm 12 \cdot 9^{a}(5)$ \\
\hline
\end{tabular}

The data are presented as means \pm S.E.M. and the number of animals is given in parentheses. Different letters signify statistical significance $(P<0 \cdot 05)$. 


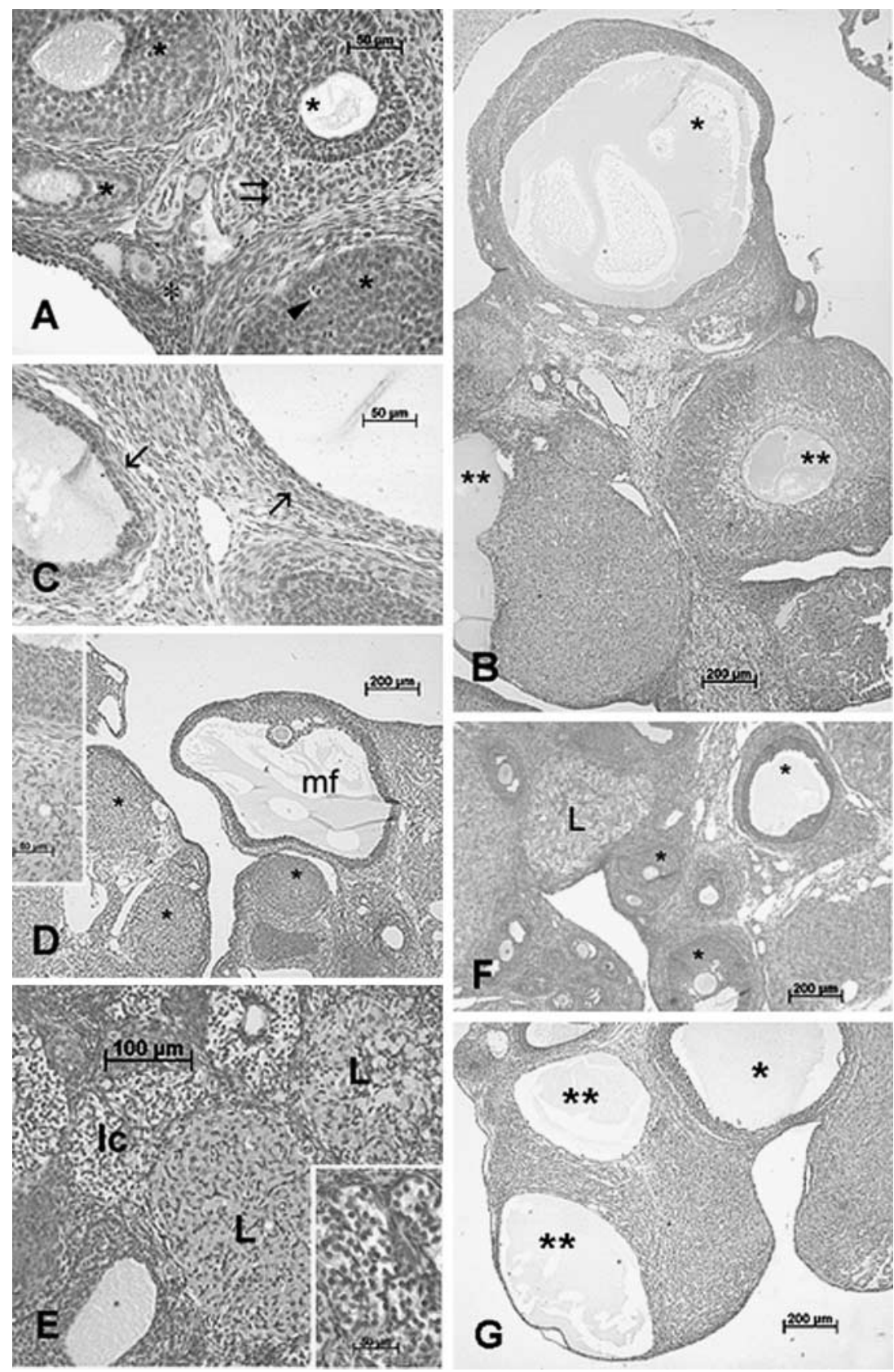

Figure 1 (A) Control group photomicrograph depicts follicles in different developmental phases $(*)$. Arrowhead identifies mitosis in the follicular cell layer and double arrows indicate interstitial cells in the ovarian stroma. (B, C) In hCG-treated females, several fluid-filled cysts ${ }^{*}$ ) can be observed. (B) The isolated asterisk shows a cyst that probably arose from a differentiating follicle, where part of the characteristic follicular cell lining is still preserved. Double asterisks show cystic structures likely to be in a corpus luteum, since thecal and follicular cells can be recognized. (C) Arrows show the altered wall of the cystic ovarian structures. (D, E) A mature follicle $(\mathrm{mf})$ and numerous corpora lutea $\left({ }^{*}\right)$ in an ovary from an insulin-treated animal. Note, $(\mathrm{E})$ the atypical morphology of the corpus luteum $(\mathrm{L})$ and the cord arrangement (Ic) of the interstitial gland (also in detail in the insert). (F, G) Normal appearance of the ovarian parenchyma of hCG-insulin-treated animals, where follicles $\left(^{*}\right)$ and part of a corpus luteum (L) can be observed. (G) Morphologically changed follicles are shown. Note the presence of a central fluid-filled area $\left(^{* *}\right)$ and the abnormal organization of the lining cells $\left(^{*}\right)$. Paraplast sections, hematoxylin and eosin. 

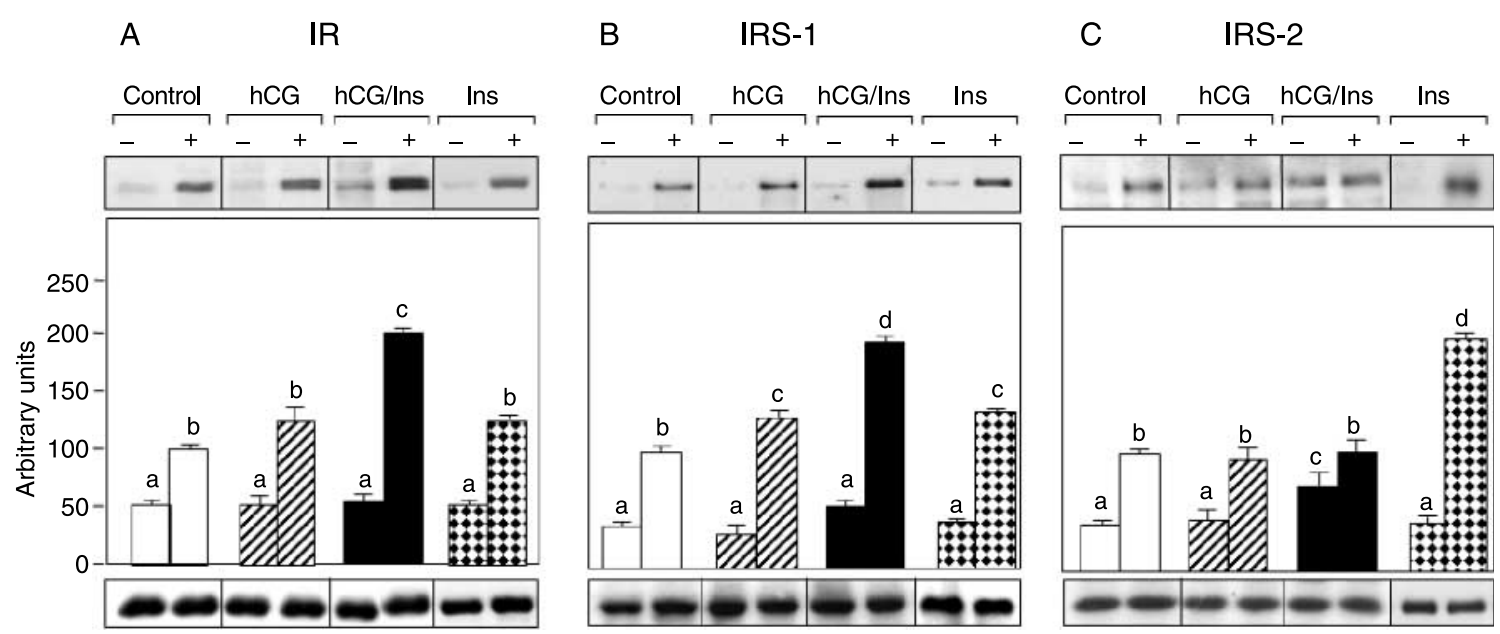

Figure 2 Insulin receptor $\beta$ subunit, IRS-1, and IRS-2 tyrosine phosphorylation and protein level. Pooled ovary extracts were immunoprecipitated with anti-IR (A), anti-IRS-1 (B), or anti- IRS-2 (C), followed by immunoblotting with antiphosphotyrosine monoclonal antibody, to analyze the degree of basal (-) or insulin-induced (+) tyrosine phosphorylation, or with each one of the same specific antibodies to analyze the protein levels. The phosphorylation levels of control (open bar), hCG-treated (hatched bar), hCG plus insulin (ins)-treated (solid bar), and insulin-treated rats (patterned bar) were evaluated using an image analyzer and are shown in the bar graph as arbitrary units (\%) of each control (before, - , and after, + , insulin stimulus). Data are the mean \pm s.E.M. of six experiments using at least five animals in each group. Different letters signify statistical significance, $P<0 \cdot 05$.

groups revealed that the extent of IRS-1 phosphorylation was a $1 \cdot 3$-fold increase $(P<0 \cdot 05)$ in both hCG alone and insulin alone-treated animals, compared with the controls. The simultaneous treatment with hCG and insulin resulted in a significantly higher insulin-induced IRS-1 phosphorylation compared with the control (Fig. 2B, bar graph) (2.3-fold increase).

The protein level of IRS-2 was similar in ovaries from all groups (Fig. 2C). In contrast, the simultaneous treatment with hCG and insulin induced an up-regulation of IRS-2 tyrosine phosphorylation, compared with the control and to each treatment alone. However, similar enhancement in IRS-2 tyrosine phosphorylation were achieved following control, hCG, and hCG plus insulin treatment. The insulin-treated group demonstrated the highest acute insulin-induced IRS-2 tyrosine phosphorylation, with a twofold increase above each group $(P<0 \cdot 05)$ (Fig. 2C, bar graph).

Strong and extensive evidence in the literature indicates that a stable high-affinity interaction exists between IRS-1 and IRS-2 and the $85 \mathrm{kDa}$ subunit of the PI 3-kinase. These interactions allow each one of these proteins to be co-precipitated by antibodies of either protein. When blots that had been previously immunoprecipitated with antibody against IRS-1 were subsequently incubated with anti-PI 3-kinase antibody (Fig. 3A), there was some PI 3-kinase immunoreactivity in the basal state of control, hCG, and insulin alone-treated rats. However, this band was significantly increased by $1 \cdot 4$-fold above each distinct condition in hCG plus insulin-treated rats, suggesting a greater association between IRS-1/PI 3-kinase under basal conditions in this group. Comparison of the bands stimulated by acute insulin injection revealed that the amount of PI 3-kinase associated with IRS-1 had the highest increase in the hCG plus insulin-treated group to approximately $1 \cdot 5$-fold above the insulin-stimulated control, hCG, and insulin-treated rats (Fig. 3A, bar graph). The IRS-2 association with PI 3-kinase was analyzed in the samples previously immunoprecipitated with anti-IRS-2 antibody (Fig. 3B), as performed for IRS-1/PI 3-kinase association. There was a faint band corresponding to basal PI 3-kinase immunoreactivity associated with IRS-2 in the control group. However, in the three treated groups, this band was significantly increased by fourfold above control, suggesting a greater association between IRS-2/PI 3-kinase, induced by each treatment, with no further increase when simultaneous treatment was imposed. In contrast to our findings for acute insulin-induced IRS-1/PI 3-kinase association, the insulin-induced association of PI 3-kinase with IRS-2 demonstrated a further increase above the basal condition only in the ovaries of the control rats (Fig. 3B, bar graph). These treatments had no effect on the protein level of the $85 \mathrm{kDa}$ subunit of PI 3-kinase (Fig. 3C).

The downstream pathways, dual phosphorylation of PKB/Akt (Fig. 4) and ERK1 and ERK2 (Fig. 5), were assessed by specific phospho-antibodies in the same ovary samples. Despite the similar degree of Akt serine phosphorylation induced by each condition, the acute insulin infusion led to a greater Akt serine phosphorylation in the ovary of rats that received both hormones together $(\sim 20$-fold increase above basal; $P<0 \cdot 05)$. On the other hand, both treatments 
A PI 3-kinase associated with IRS-1

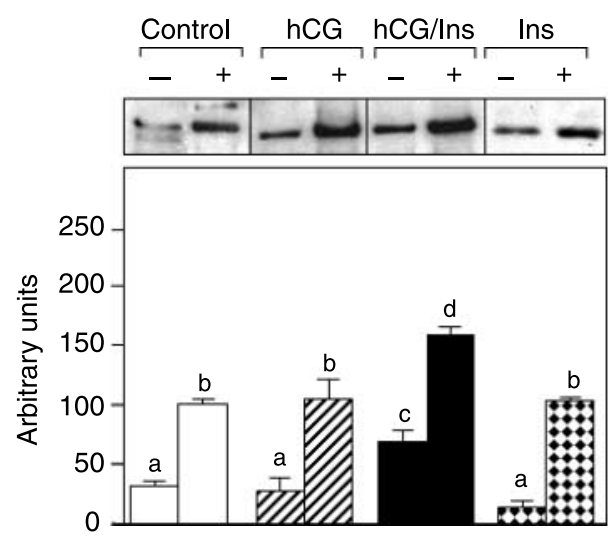

B PI 3-kinase associated with IRS-2
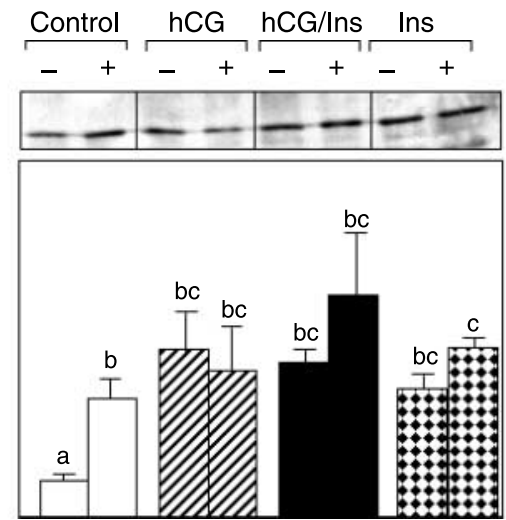

C PI 3-kinase

hCG/
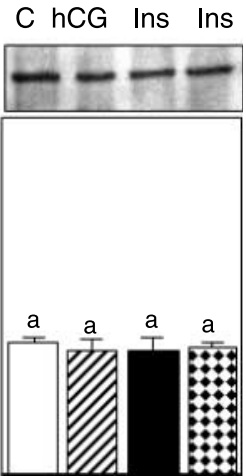

Figure $3 \mathrm{PI}$ 3-kinase association with the IRS, IRS-1 and IRS-2, and protein level. Pooled ovary extracts were immunoprecipitated with anti-IRS-1 (A) or anti-IRS-2 (B) antibodies, followed by immunoblotting with antibody against the 85 kDa subunit of the PI 3-kinase. The amount of PI 3-kinase is either associated with each IRS (IRS-1, A, or IRS-2, B) or not (C) of control (open bar), hCG treated (hatched bar), hCG plus insulin (Ins)-treated (solid bar), and insulin-treated rats (patterned bar) were evaluated using an image analyzer and are shown in the graph bar as arbitrary units (\%) of each control (before, - , and after, + , insulin stimulus). Data are the mean \pm s.E.M. of six experiments using at least five animals in each group. Different letters signify statistical significance, $P<0 \cdot 05$.

with hCG alone or with insulin led to a greater Akt threonine phosphorylation compared with the control and insulintreated alone rats (Fig. 4B). Despite these changes in the phosphorylation status, the $\mathrm{PKB} / \mathrm{Akt}$ protein level was similar in all groups (Fig. 4C).
The distinct hormone treatment had no impact on the phosphorylation degree of either ERK1 or ERK2 or on their protein levels. The acute insulin administration induced enhancement in dual ERK1 and ERK2 phosphorylation that was similar in all groups (Fig. 5A, B).
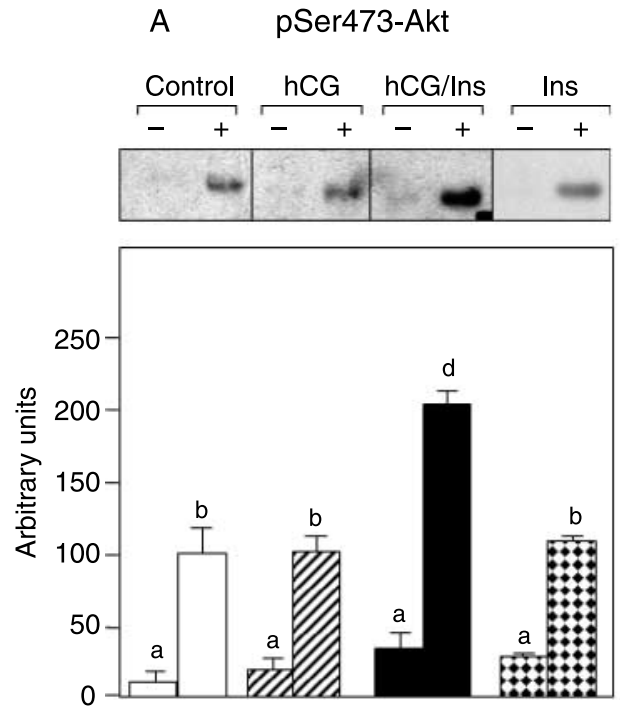

B
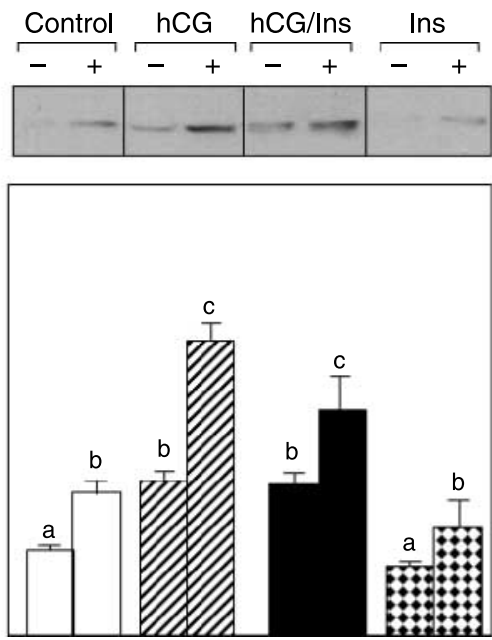

C Akt
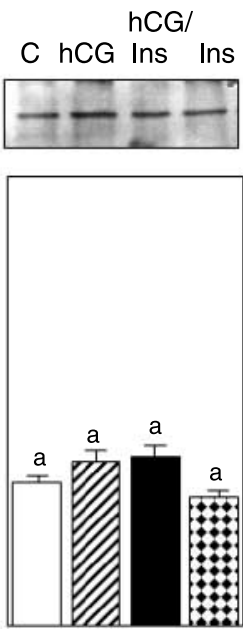

Figure 4 Akt serine and threonine phosphorylation status and protein level. Pooled ovary extracts were submitted to SDS-PAGE and immunoblotted with anti-phospho-Ser473-Akt (A), or anti-phospho-Thr308 Akt (B), or anti-Akt (C) antibodies. The protein level and phosphorylation degree of Akt of control (open bar), hCG-treated (hatched bar), hCG plus insulin (Ins)-treated (solid bar), and insulin-treated rats (patterned bar) were evaluated using an image analyzer and are shown in the bar graph as arbitrary units $(\%)$ of each control (before, - , and after, + , insulin stimulus). Data are the mean \pm s.E.M. of four experiments using at least five animals in each group. Different letters signify statistical significance, $P<0 \cdot 05$. 

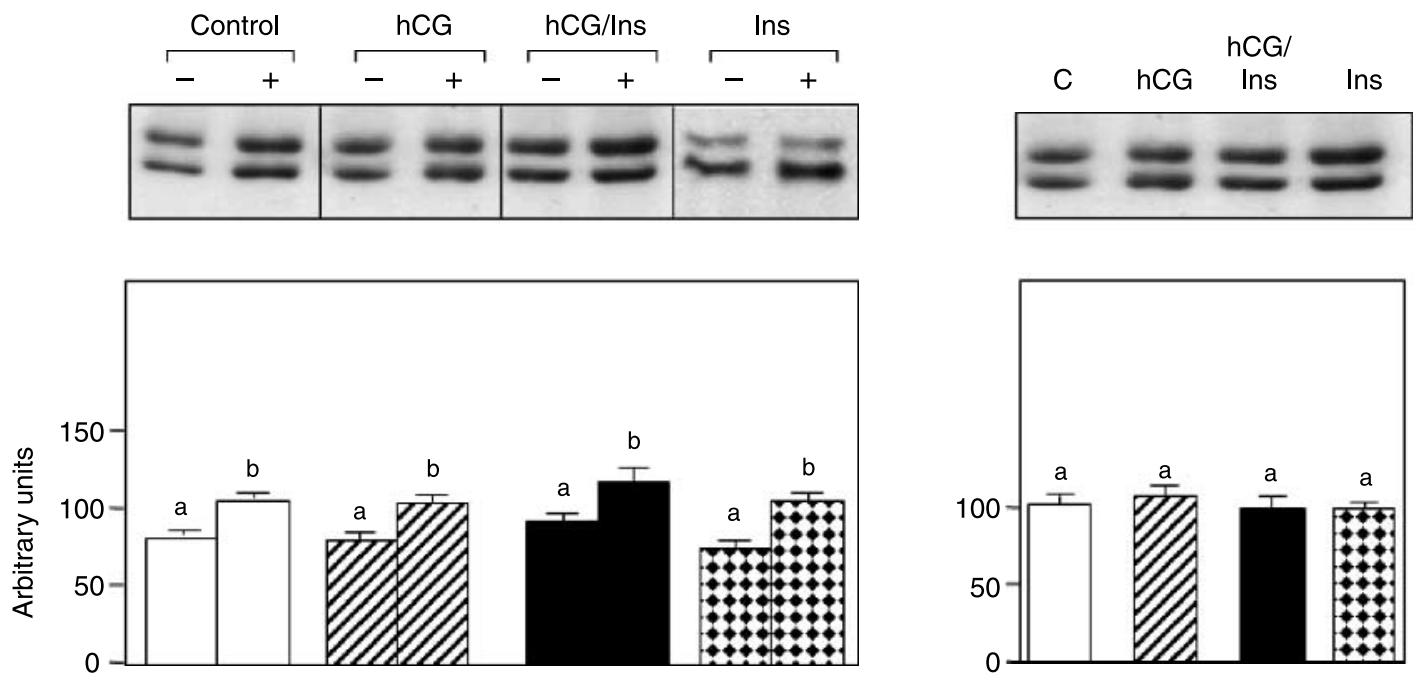

Figure 5 ERK-1 and ERK-2 phosphorylation status and protein level. Pooled ovary extracts were submitted to SDS-PAGE and immunoblotted with anti-phospho-ERK-1 and ERK-2 (A), also known as p42/44 mitogen-activated protein kinase, or anti-ERK-1 and ERK-2 (B) antibodies. The phosphorylation degree and protein level of ERK-1 and ERK-2 of control (open bar), hCG-treated (hatched bar), hCG plus insulin (Ins)-treated (solid bar), and insulin-treated rats (patterned bar) were evaluated using an image analyzer and are shown in the bar graph as arbitrary units (\%) of each control (before, -, and after, + , insulin stimulus). Data are the mean \pm s.E.M. of four experiments using at least five animals in each group. Different letters signify statistical significance, $P<0 \cdot 05$.

\section{Insulin-induced IRS-1 and Akt serine phosphorylation in the hind limb skeletal muscle of rats}

The skeletal muscle gastrocnemius was used as a classical insulin target (Fig. 6). The IRS-1 tyrosine phosphorylation status after insulin acute infusion was increased in the hCGtreated group by $1 \cdot 5$-fold $(P<0 \cdot 05)$, compared with the control. In the hyperinsulinemic rats, there was a significant decrease in insulin-induced IRS-1 tyrosine phosphorylation compared to the control $(P<0 \cdot 05)$. The hyperinsulinemic hCG-treated rats had a similar insulin-induced tyrosine phosphorylation of IRS-1 to the control animals (Fig. 6A). The skeletal muscle Akt serine phosphorylation, induced by insulin, showed a significant reduction in the hyperinsulinemic group compared with the control, while the other two groups presented similar patterns of phosphorylation to that detected in control animals (Fig. 6B).

\section{Discussion}

The results of the present study demonstrate that chronic hCG treatments, alone or with insulin, are able to simulate some features of PCOS: unabated stimulation by LH-like activity, cysts, and elevation in serum androstenedione. In contrast, hyperinsulinemia alone presented two distinctive characteristics when compared with controls: the corpus luteum was smaller and persistent numerous interstitial cells were observed to be unusually arranged in cord-like clusters.
Despite the microscopic aspect of steroidogenic activity and the evidence in the literature suggesting a positive role of insulin in androgen synthesis, we did not detect any changes in the androstenedione concentration level at the end of the insulin treatment alone.

Our results showed that simultaneous treatment with hCG and insulin, which induced more pronounced changes in ovarian morphology, also induced an up-regulation in insulin receptor and IRS-1 tyrosine phosphorylation, and in IRS-1 association with PI 3-kinase stimulated by acute insulin infusion. Conversely, insulin-induced IRS-2 tyrosine phosphorylation was increased in the ovary of hyperinsulinemic rats, suggesting that this pathway is up-regulated in this situation. These IRS- 1 and IRS- 2 docking proteins can bind and activate PI 3-kinase; one target of this phospholipid enzyme is $\mathrm{PKB} / \mathrm{Akt}$ and its upstream activator, PDK. The serine phosphorylation of $\mathrm{PKB} / \mathrm{Akt}$ was markedly increased in ovaries of rats treated with hCG plus insulin, in a pattern similar to that detected for IRS-1 phosphorylation and association with PI3-kinase. However, the hCG treatment, alone or with insulin, induced an enhancement in Akt threonine phosphorylation similar to that detected for IRS2/PI 3-kinase association. Full activation of Akt requires the two phosphorylation events, and both IRS-1 and IRS-2 associations with PI 3-kinase may mediate the modulation of Akt in ovaries.

Akt activation is involved in cell growth, inhibition of apoptosis, and granulosa cell survival (Lawlor \& Alessi 2001, Johnson et al. 2001). Our data demonstrated that chronic 
A

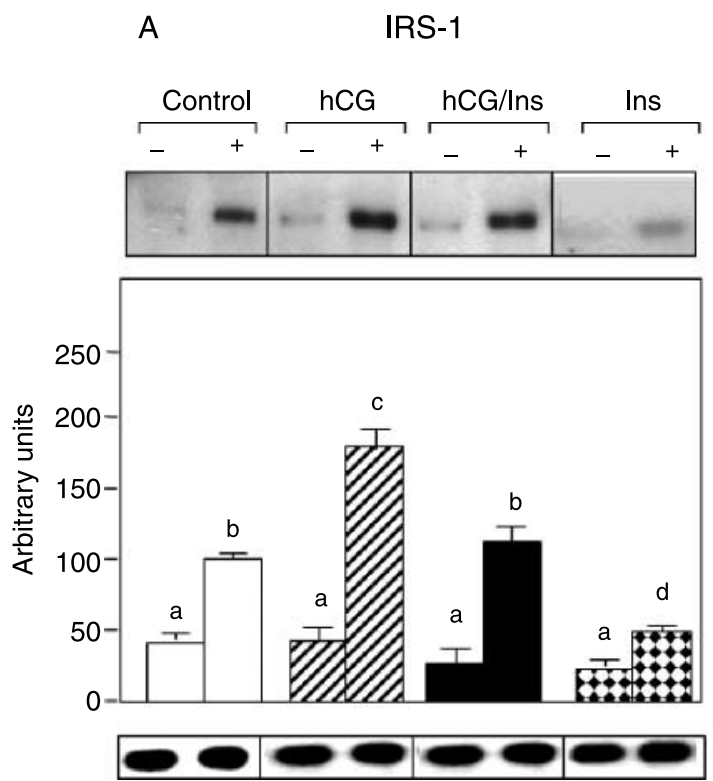

B

pSer473-Akt
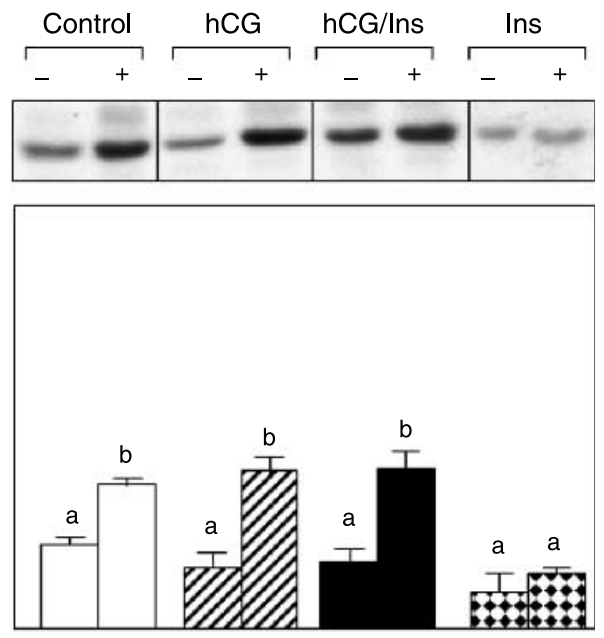

Figure 6 Effect of chronic treatment with low doses of hCG with or without hyperinsulinism, on IRS-1, and Akt phosphorylation on Ser473 in the skeletal muscle of non-pregnant rats in vivo. Gastrocnemius muscle extracts were used for immunoprecipitation assay with anti-IRS-1 antibody (A) or treated as whole extract tissue and submitted to SDS-PAGE and immunoblotted with anti-phospho-Ser473-Akt (B). The previously immunoprecipitated samples were immunoblotted with antiphosphotyrosine monoclonal antibody to analyze the degree of basal (-) or insulin (Ins)induced (+) tyrosine phosphorylation, or with anti-IRS-1 antibody to analyze the protein levels. The phosphorylation levels of control (open bar), hCG-treated (hatched bar), hCG plus insulin-treated (solid bar), and insulin-treated rats (patterned bar) were evaluated using an image analyzer and are shown in the bar graph as arbitrary units (\%) of each control (before, - , and after, + , insulin stimulus). Data are the mean \pm s.E.M. of four experiments using at least five animals in each group. Different letters signify statistical significance, $P<0 \cdot 05$.

treatment with hCG, alone or plus insulin, enhanced Akt phosphorylation and may indicate a role for this intracellular mechanism in the development of follicular cysts in this animal model.

Previous data from our group demonstrated an acute positive crosstalk between LH and insulin in Akt serine phosphorylation without additive effects on ERK phosphorylation (Carvalho et al. 2003). In the present study, we show that chronic treatment with hCG and insulin induced a similar crosstalk in the Akt phosphorylation and ERK pathway. Recent evidence indicates that stimulation of the ERK cascade inhibits steroidogenesis in granulosa cells. ERK pathways were also found to inhibit the expression of the CYP17 gene in an adrenocortical cell line (Sewer \& Waterman 2003, Munir et al. 2004, Nelson-Degrave et al. 2005).

Despite the insulin-induced enhancement in IRS-1 tyrosine phosphorylation in skeletal muscle from hCGtreated rats, insulin treatment alone induced insulin resistance, as demonstrated by decreased IRS-1 and Akt phosphorylation. Conversely, the associated hCG plus insulin treatment had no effect on these intracellular pathways in skeletal muscle, suggesting that non-redundant pathways are involved in these modifications. Interestingly, despite the reduced insulin signaling in muscle, hyperinsulinemia alone had no effect on the IRS-1/PI 3-kinase pathway in ovary. This tissuespecific modulation of insulin signaling has also been previously described by comparing muscle and adipose tissues in other animal models of insulin resistance presenting as hyperinsulinemia (Prada et al. 2005, Ueno et al. 2005). However, to our knowledge, these are the first data to demonstrate such a tissue-specific modulation of the IRS-1/ PI 3-kinase/Akt pathway in muscle and ovary. In summary, our data show that chronic treatment with hCG or hCG plus insulin can induce changes in ovaries that simulate PCOS. In these situations, increases occur in the insulin-induced IRS/ PI 3-kinase/Akt pathway in the ovary, suggesting that the activation of this pathway may have a role in the development of PCOS.

\section{Acknowledgements}

We gratefully acknowledge Dr C Franci for the LH determination by RIA. We also thank Mrs Luciene M Ribeiro and Mr L Janeri for technical assistance, and the NIDDK's National Hormone \& Pituitary Program and A F Parlow for the hCG. This work was supported by grants from Conselho Nacional de Pesquisa (CNPq) and Fundação de Amparo à Pesquisa do Estado de São Paulo (FAPESP). The authors declare that there is no conflict of interest that would prejudice the impartiality of this scientific work. 


\section{References}

Carvalho CRO, Carvalheira JB, Lima MH, Zimmerman SF, Caperuto LC, Amanso A, Gasparetti AL, Meneghetti V, Zimmerman LF, Velloso LA et al. 2003 Novel signal transduction pathway for luteinizing hormone and its interaction with insulin: activation of janus kinase/signal transducer and activator of transcription and phosphoinositol 3-kinase/Akt pathways. Endocrinology 144 638-647.

Dunaif A 1997 Insulin resistance and the polycystic ovary syndrome: mechanism and implications for pathogenesis. Endocrine Reviews 18 774-800.

Dunaif A, Futterweit W, Segal KR \& Dobrjansky A 1989 Profound peripheral insulin resistance, independent of obesity, in the polycystic ovary syndrome. Diabetes 38 1165-1174.

Franks S, Gilling-Smith C, Watson H \& Willis D 1999 Insulin action in the normal and polycystic ovary. Endocrinology and Metabolism Clinics of North America 28 361-378.

Johnson AL, Bridgham JT \& Swenson JA 2001 Activation of the Akt/protein kinase B signaling pathway is associated with granulosa cell survival. Biology of Reproduction 64 1566-1574.

Lawlor MA \& Alessi DR 2001 PKB/AKT: a key mediator of cell proliferation, survival and insulin responses? Journal of Cell Science 114 2903-2910.

Legro RS, Blanche P, Kraus RM \& Lobo RA 1999 Alterations in low-density lipoprotein and high-density lipoprotein subclass among Hispanic women with polycystic ovary syndrome: influence of insulin and genetics factors. Fertility and Sterility 72 990-995.

Munir I, Yen HW, Geller DH, Torati D, Bierden RM, Weitsman SR, Agarwal SK \& Magoffin DA 2004 Insulin augmentation of 17alpha-hydroxylase activity is mediated by phosphatidyl inositol 3-kinase but not extracellular signalregulated kinase-1/2 in human ovarian theca cells. Endocrinology 145 17511783.

Nelson-Degrave VL, Wickenheisser JK, Hendricks KL, Asano T, Fujishiro M, Legro RS, Kimball SR, Strauss JR 3rd \& McAllister JM 2005 Alterations in mitogen-activated protein kinase kinase and extracellular regulated kinase signaling in theca cells contribute to excessive androgen production in polycystic ovary syndrome. Molecular Endocrinology 19 379-390.

Nestler JE, Jakubowicz DJ, Vargas AF, Brik C, Quintero N \& Medina F 1998 Insulin stimulates testostrone biosynthesis by human thecal cells from women with polycystic ovary syndrome by activating its own receptor and using inositolglycan mediators as the signal transduction system. Journal of Clinical Endocrinology and Metabolism 83 2001-2005.

Poretsky L, Clemons J \& Bogovich K 1992 Hyperinsulinemia and human chorionic gonadotropin synergistically promote the growth of ovarian follicular cyst in rats. Metabolism 41 903-910.

Poretsky L, Cataldo NA, Rosenwarks Z \& Giudice LC 1999 The insulinrelated ovarian regulatory system in health and disease. Endocrine Reviews 20 $535-582$.

Prada PO, Zecchin HG, Gasparetti AL, Torsoni MA, Ueno M, Hirata AE, Corezola do Amaral ME, Hoer NF, Boschero AC \& Saad MJ 2005 Western diet modulates insulin signaling, c-jun N-terminal kinase activity, and insulin receptor substrate-1ser 307 phosphorylation in a tissue-specific fashion. Endocrinology 146 1576-1587.

Saltiel AR \& Kahn CR 2001 Insulin signaling and the regulation of glucose and lipid metabolism. Nature $\mathbf{4 1 4}$ 799-806.

Saltiel AR \& Pessin JE 2002 Insulin signaling pathway in time and space. Trends in Cellular Biology 12 65-71.

Sewer MB \& Waterman MR 2003 CAMP-dependent protein kinase enhances CYP17 transcription via MKP-1 activation in H295R human adrenocortical cells. Journal of Biological Chemistry 278 8106-8111.

Ueno M, Carvalheira JB, Tambascia RC, Bezerra RM, Amaral ME, Carneiro EM, Folli F, Franchini KG \& Saad MJ 2005 Regulation of insulin signalling by hyperinsulinaemia: role of IRS-1/2 serine phosphorylation and the mTOR/p70 S6K pathway. Diabetologia 48 506-518.

Willis D \& Franks S 1995 Insulin action in human granulosa cells from normal and polycystic ovaries is mediated by the insulin receptor and not the type-I insulin-like growth factor receptor. Journal of Clinical Endocrinology and Metabolism 80 3788-3790.

Received in final form 12 March 2006

Accepted 7 April 2006

Made available online as an Accepted Preprint

9 May 2006 